\title{
Yoga for physical and mental health - Can possibly aid in prevention and management of COVID19 infection?
}

\author{
Nitesh Sharma ${ }^{1 *}$ \\ ${ }^{1}$ Research scholar, Centre for value education in engineering, Indian Institute of Technology, Delhi, India \\ *Corresponding author email: nitesh.dsvv@gmail.com \\ https://doi.org/10.36018/dsiij.v16i.161
}

\begin{abstract}
COVID19 pandemic is global infectious disease caused by SARS Corona Virus 2. The pandemic so far has affected more than 200 countries and territories causing more than 12,552,765 human infections and 561,617 human deaths. The situation has created global emergency crisis and is rapidly spreading. The infected humans are known to have low immunity and once infected developed conditions such as acute respiratory distress syndrome, breathlessness, severe dyspnea, tachypnea, respiratory distress, hypoxia and cardiac arrest, etc. In addition, people with chronic diseases like diabetes, hypertension, cardiovascular disorders, Chronic obstructive pulmonary disorder (COPD), asthma, and elderly people with weakened immune systems are known to be more prone to catch the infection. So far no treatment is clinically proven and available, but many are under investigations; the best approach to fight against the disease is prevention and management of COVID19 infection. Yoga, meditation, and yogic bio-cleansing practices previously evidenced for general immune boosting capacity, and are also evidenced for the management of respiratory disorders, non-communicable disorders such as diabetes, cardiovascular diseases, etc, and also for psychological disorders and ailments; by reviewing these studies, in the presented study, it was attempted to shed a light on the possibility of supporting role of Yoga for improving physical and mental health in the patients with COVID19 with respiratory disorders, co-morbidities (diabetes and cardiovascular disorders), decreased immune function, and psychological illness.
\end{abstract}

Keywords. COVID19, Yoga, Yogic practices, Co-morbidities, Immunity, Diabetes, Cardiovascular diseases, Respiratory illness, and Mental health 


\section{Introduction}

COVID19 is a rapidly spreading infectious disease that has caused global pandemic due to recently emerged novel Corona Virus called Severe Acute Respiratory Syndrome Corona virus 2 (SARS-CoV2). The place of an outbreak of COVID19 infection was the city of Wuhan, located in Hubei province of China, and it started in the month of December 2019 and later on it spread globally (1).

COVID19 virus is known to infect both human beings and animals (2). In human beings, it spreads rapidly from person to person through close contacts, or by tiny droplets containing viruses which are expelled in coughing and sneezing from an infected person to non-infected person entering in their mouth or nasal passage and causing infection (2). This disease has become a global pandemic and serious concern for the human beings as it is spreading rapidly. It has covered around 216 countries and territories, and has infected about 12,552,765 people around the world causing the deaths of 561,617 people as per World Health Organization as of July 12, 2020, at 4:49 pm CEST.

\section{Symptoms and co-morbidity}

The known most common symptoms in COVID19 infected cases include fever, dry cough, tiredness, headaches and body aches, sore throat, nasal congestion, and diarrhea (2). These symptoms may range from mild to moderate and then severe. Around $80 \%$ of people recover from this illness (2). But one out of five patients may have the chance to develop severe respiratory symptoms. The older people who have weak immunity and people with co-morbidities like hypertension, diabetes, obesity, kidney problems, liver infection, heart or lung problems and cancer are at high risk of developing serious illnesses due to COVID19 infections (3). Guan et al. (2020) confirmed this fact by the study report that COVID19 patients with co-morbidity yield poorer clinical outcomes than those without it (4). Hence, the patients with co-morbidity are at higher fatality risk than those without it. The emergency sign and symptoms caused by this disease are breathing trouble, continuous chest pain, blue lips or face, inability to stay awake, and developing new confusion (3).

To combat these symptoms of COVID19 infection the immune response needs to be stronger because weak and mal-adjusted immune response is known to result in pathology and impaired pulmonary gaseous exchange. The respiratory symptoms developed in this disease can be classified as mild, moderate, and severe (5). Mild symptoms are like non-pneumonia or mild pneumonia along with symptoms of the upper respiratory tract, cough, nasal congestion, soreness of throat, mild to moderate fever, malaise, muscle pain, headaches, vomiting, diarrhea, loss of taste and smell. Moderate symptoms include cough and shortness of breath without the sign of severe pneumonia. Severe symptoms include fever along with severe dyspnea, tachypnea ( $>30$ breaths/ min), respiratory distress, and hypoxia i.e. SPO2 less than 90\% (5).

\section{Psychological problems in COVID19 pandemic}

In addition, COVID19 infection has created psychological problems such as stress, anxiety, and depression including like panic and fear of death. A survey conducted by Wang et al. (2020) in China on psychological impact during the initial outbreak of COVID19 and the result of the study revealed moderate to severe depressive symptoms, anxiety symptoms, and stress level during this pandemic condition (6).

These psychological stresses may inhibit immune responses. Andersen et al. (1998) studied the physiological effect of stress on immune function and the data showed that stress inhibited the cellular immune responses including NK cells and T-cell responses (7). Another study conducted by Torales et al. (2020) reported that during the Korean MERS$\mathrm{CoV}$ outbreak in 2015, the patients treated with hemodialysis in isolation reported physiological distress and significant delay in normalization during hemodialysis when compared to the patients of non-stressful conditions having the same treatment (8). Due to psychological distress, anxiety, and depression, there was a reduction in the immune

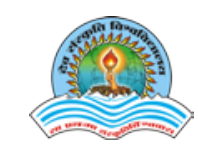


responses and significant delay in the recovery of the patients. Considering the reported findings, it could be predicted that in the global pandemic of COVID19, it could aggravate mental health issues having long-lasting effects on health problems.

Available treatment options and potential role of Yoga

Regarding available options for the treatment of COVID19, WHO declared that to date there is no specific treatment of this disease, any medicines and vaccines are available right now, though many treatments are under clinical trials. Doctors and researchers are trying and testing a variety of possible treatments. Considering the dire need of the treatment and no availability of treatment, Food and Drug Administration of USA, approved some drugs in the management of COVID19 such as hydroxychloroquine and chloroquine (anti- malarial drugs), and remdesivir (an antiviral drug) (3).

Besides these available options and ongoing approaches for finding treatments, the preventive measures like wearing a mask, hand sanitizing, social distancing, staying home, eating healthy foods, doing regular physical activities or exercises, taking adequate sleep, and performing yoga, pranayama, and meditation can be useful measures to prevent COVID19 spread at maximum strength.

The practice of yoga and meditation in this situation can be found helpful in releasing COVID19 related stress and anxiety and can also reduce the complications of this disease by boosting and improving immune and respiratory functions. In addition, previously many studies evidenced the beneficial effect of yoga in lifestyle disorders such as diabetes, hypertension, and other cardiovascular disorders. In COVID19 infected patients, diabetes, hypertension and cardiovascular diseases are factors for co-morbidity death. Hence, Yogic management in such conditions would possibly help in prevention and management of the COVID19 infection. Here, the presented study aimed to evaluate the potential role of yoga in the management of the physical and mental diseases and ailments which are specifically symptoms of COVID19 infected patients through reviewing published studies.

\section{Yoga}

Yoga is an ancient science of India for culturing divinity in ourselves. The word yoga is derived from the Sanskrit word 'Yuj' which means union with the divine. Yogic practices consist of mind-body practices which include asana (yogic postures), pranayama, and meditation. Yogi practices are known to bring psychological and physiological changes in the body to bring harmony and homeostasis at the physical and mental level of the practitioners.

Yoga influences the life of practitioner at every dimension i.e. physical, mental, and spiritual. Maharishi Patanjali has described eight limbs or stages of Yoga i.e. Yama (social disciplines), niyama (spiritual disciplines), asana (yogic postures), pranayama (yogic way of breathing), pratyahara (control over senses), dharana (concentration), dhyana (meditation), and samadhi (enlightment). The practice of these eight limbs of yoga is for spiritual and comprehensive progress.

There has been ample research evidence indicating therapeutic benefit of yoga for treatment and management of various diseases and ailments. In addition, Yogic practices also found therapeutically effective in treating and managing psychological disorders and conditions such as stress, anxiety depression, and post-traumatic depression, etc described in this study. In addition, studies also had showed therapeutic benefits of six Yogic-bodydetoxification processes (shatkarma) i.e Dhauti, Basti, Neti, Nauli, Trataka, and Kapalabhati as a standalone intervention or along with combination.

\section{Therapeutic effect of Yoga in diabetes}

A study by B.K Sahay (2007) evaluated the role of yogic practices on glycemic control and insulin kinetics in diabetic individuals and confirmed the usefulness of yoga in lowering down the blood glucose levels both fasting and postprandial. In addition, with Yogic practices, a good glycemic 
status was maintained for a longer time along with the reduction in requirement of drug and the frequency of acute complications like ketosis and infection (9). In a systematic review of yoga-based intervention programs on Diabetes Mellitus 2 adult patients indicated significant beneficial changes in risk profiles like glucose tolerance, insulin sensitivity, lipid profiles, oxidative stress, blood pressure, coagulation profiles, sympathetic activation, and pulmonary function (10). Another study had also shown that a significant reduction in the parameters of plasma insulin, total cholesterol, and LDL-C levels was achieved with eight weeks of yoga intervention (11).

Besides Yogic packages, practices of specific yogic bio-cleansing processes (shatkarma) had also been shown to have beneficial effects in the management of diabetes. For example, Jindal \& Joshi conducted a study on 20 diabetic men and found that Vamana (an emetic cleansing therapy) had a significant role in the reduction of fasting blood sugar FBS and postprandial blood sugar PPBS (12). In addition, the yogic kriyas like agnisara and kapalbhati along with asana and pranayama had reduced Glycated Haemoglobin (HbA1C) levels in diabetic patients (13) indicating potential role of Yoga in the management of the diabetes. Thus in COVID19 patients with Co-morbidity of diabetes, Yogic package could possibly support in fight against infection.

\section{Therapeutic effect of Yoga on hypertension}

Many studies showed that Yogic practice such as mind-body interventions normalized or lowered blood pressure in pre-hypertensive and hypertensive persons. For instance, a study of 20 weeks yoga intervention program on $60 \mathrm{HIV}$-infected individuals with mild to moderate cardiovascular risk factors, significantly reduced blood pressure in the group treated with yoga-practices compared to that of group receiving standard treatment (14). Also, in the review of 17 studies, Hagins, Selfe, and Innes demonstrated that yoga interventions having postures, meditation, and breathing as three basic elements had a modest but significant effect in lowering of BP both systolic and diastolic blood pressure (15). In another systematic review on Yoga and hypertension involving 39 cohort studies, 30 non-randomized control trials, 48 randomized control trials, and 3 case reports, Tyagi \& Cohen (2014) reported the effectiveness of yoga in lowering down the BP in both normotensive and hypertensive patients (16).

Almost 2 decades back, in an interesting randomized-control-trial on with and without Yogic intervention for observing the differences in blood pressure was conducted by Murugesan et al. (2000). The study showed statistical reduction in blood pressure in the group treated with Yogic intervention compared to no-treatment control group (17).

Apart from these, many studies evidenced the same indicating potential role of Yoga in management of the hypertension and its complications. Thus in COVID19 patients with Co-morbidity of hypertension and relevant complications, Yogic package could possibly support in fight against infection.

\section{Impact of yoga on respiratory illness}

As COVID19, patients showed respiratory disorders and associated complications and conditions such as shortness of breath, hypoxia, inflammation of lung, dyspnea, fall of oxygen saturation below 90\%, pulmonary edema, acute respiratory distress syndrome and cardiac arrest (18); several studies have reported that yoga asana, pranayama, meditation, yogic-cleansing practices such as Jalaneti (Saline nasal irrigation), Vamana dhauti (an emetic cleansing exercise) had been found significantly effective in improving the condition of the respiratory disorders as described following, hence potentially could aid in treatment of COVID19 patients with respiratory complications.

A study by Rubago et al., (2002) indicated that daily practice of hypertonic saline nasal irrigation (Jalaneti) reduced complains of sinusitis and occurrence of acute exacerbation in the upper respiratory tract (19). In other study, Tano et al., (2004) found that 
symptoms such as rhinitis, nose block, fever, cough, soreness of throat, and the frequency of upper respiratory tract infections were significantly reduced by the daily nasal spray with saline on a healthy population for 10 days compared to that of 10 days of observational period (20). Also the efficacy of saline nasal irrigation (Jal-neti) on allergic rhinitis was assessed in other study and found that $40^{\circ} \mathrm{C}$ saline nasal irrigation was effective in reducing the sneezing, nasal obstruction, and the levels of histamine and leukotriene (21).

Nagendra \& Nagarathna, (1986) assessed the role of daily yoga practices including weekly cleansing practices like neti and vaman-dhauti kriyas on 570 patients of asthma who were followed up from 3 to 54 months and showed significant improvements in most of the specific parameters of asthma (22). A similar study was done by Ranjita et al., (2016) to assess the effectiveness of 12 weeks of yoga program including the cleansing practices (neti and dhauti), asana, pranayama, and meditation on 81 coal miner COPD patients; the result showed significant reduction $(\mathrm{p}<0.001)$ in dyspnea, fatigue, and pulse rate (PR) and significant improvements $(\mathrm{p}<0.001)$ in exercise capacity and oxygen saturation $\left(\mathrm{SPO}_{2}\right)$ percentage in patients with yogic intervention compared to that of control group (23).

Besides these, pranayama were also evaluated for respiratory complications and it was observed that the deep breathing pranayama with slow respiration rate is beneficial for respiratory complications. A study was conducted to evaluate the effect of slow yogic breathing exercise on chemoreflex hypoxic and hypercapnic responses, which showed decrease in chemoreflex hypoxic and hypercapnic responses compared to the control group (24). Another study conducted to assess the effect of breathing rate on oxygen saturation and exercise performance on 15 chronic heart failure (CHF) patients (who practiced controlled guided pranayama at the rate of 6 breaths per minute of respiratory rate for one month) showed reduced dyspnoea and improved $\mathrm{SPO}_{2}$; in addition resting pulmonary gas exchange and exercise performance were also increased in CHF patients compared to baseline (25).

In addition, a review of 9 studies evaluating yogic effect on pulmonary function showed that yoga improved pulmonary functions such as maximum inspiratory pressure, maximum expiratory pressure, maximum voluntary ventilation, forced vital capacity, forced expiratory volume (FEV), and peak expiratory flow rate (26). In the same line, a study of Yogic package was conducted by Sodhi et al. (2009) on 120 asthmatic patients who were randomized into two groups with 60 patients in each. The outcome measured the pulmonary function tests at the baseline, 4 weeks and 8 weeks in both groups treated with and without yoga. The yogic treatment showed a statistically significant increase $(\mathrm{P}<0.01)$ in predicted-peak-expiratory-flow-rate, forcedexpiratory-volume (FEV), forced-vital-capacity, forced-mid-expiratory-flow in $0.25-0.75$ seconds at 4 week and 8 weeks compared to that of control group (27). The study indicated that yoga breathing exercises when used with standard pharmacological treatment significantly improves pulmonary functions in bronchial asthmatic patients. Similar positive report was also reported by Nagarathna \& Nagendra in 1985, which was conducted on 53 patients of asthma, who were given yoga training for two weeks involving yoga asana, pranayama, meditation and a devotional session for 65 minutes daily. Matched groups with age severity of disease conditions, medications were used as control. The result showed in the yoga group there was a significantly greater improvement in the number of asthmatic attacks per week, scores for drug treatment and peak flow rate (28). Thus, these studies revealed the efficacy of yoga in the long term management of bronchial asthma.

In addition, Liu et al. (2014) conducted a systematic review and Meta analysis of 5 randomized control trials to assess the effect of yoga in patients with COPD and the findings revealed that yoga training had improved forced expiratory volumes FEV1 and FEV1\% significantly (29). Such findings were also supported by other study of Donesky-Cuenco et al

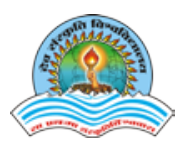


(30). In addition, quality of life and lung function parameter including maximum inspiratory and expiratory volumes were also shown to improve in COPD patients after 6 weeks of yoga training (31). Reviewing these evidences indicated regular practice of yoga could help in improvement of pulmonary function and also could possibly prove beneficial for prevention and management of respiratory disorders.

\section{Possible impact of yoga on immune system}

Disturbed or malfunctioning of the immune system and elevated levels of C-reactive proteins (CRP) are the chief characteristics seen in severely affected COVID19 patients (32). In the time of incubation or non-severe stages of the disease the body requires a specific adaptive immune response to eliminate the virus and stop the progression of disease to severe stages (33). Yoga practices previously were shown significant usefulness in improving the immune function as reported by many research studies thus potentially could be beneficial in COVID19 patients.

A randomized control trial reported significant reduction of CRP in the yoga group as compared to control groups in patients with heart failure and risks of inflammation (34). Infante et al. (2014) conducted a study on immune cells and anxiety in transcendental meditation practitioners and control group; it revealed that transcendental meditation practitioners have shown lower scores on the STAI anxiety scale and the slight improvement in the immune cells CD3, CD4 and CD8 compared to that of in control group (35). In other study, Yoga practice shown to have significant increase in immune-related cytokines, such as interleukin IL-12, and interferon IFN- $\gamma$, in serum $(\mathrm{p}<0.05$ or $\mathrm{p}=0.01)$ (36).

Interferon IFN-gamma acts as a central regulator of cell mediated immunity and functions as an antiviral, antitumor, and immune regulator (37). Regular practice of yoga may elevate the level of IL-2 and IFN-gamma which stimulates the cell mediated immunity (38). In a randomized control trial study, cytokines such as IFN-gamma, known involved in cell mediated immunity, were also found to increase in the yoga group (36), and buffering effect of yoga on INF-gamma was also shown in another randomized control trial (39).

A study shows the effect of Yogic Intervention (containing loosening exercises, surya-namaskar, yogic postures, pranayama, and relaxation technique for one month) showed significant improvement in CD4 cell count compared to the control group (40). Further, a study was conducted on 200 breast cancer survivors who were randomized into two groups. The experimental group received 90 minutes of yoga session twice per week for 3 months and the control groups were on usual routine. At the end of 3 months post-treatment, fatigue was lowered in the yoga group $(\mathrm{P}=0.002)$, vitality was higher $(\mathrm{P}=0.01)$, and inflammatory cytokines such as IL-6 $(\mathrm{P}=0.027)$, TNF- $\alpha(\mathrm{P}=0.027)$, and IL-1 $\beta(\mathrm{P}=0.037)$ were lower for yoga participants when compared with the control group (41). Another study on breast cancer survivors was done to investigate the levels of inflammatory cytokine (sTNF-rII) and the result reported that sTNF-rII increased in the control group but remained stable in the yoga group indicating that yoga acts as a buffering effect on abnormal TNF alpha activity (42).

Study has shown that blocking of harmful cytokines such as IL-6, IL-1, and TNF-alpha may benefit Covid patients (33). Also higher levels of IL-6 were reported in several studies in critical patients of COVID19 (43). Several studies previously had shown that Yogic practices reduced cytokines which were known to be harmful in COVID19 patients. For example, an eight week of yoga intervention program it was seen that there was reduced harmful cytokine secretion including IL-6, TNF-alpha, IL-1beta compared to baseline and compared to control group (11). Effectiveness of yoga in reducing the IL1 beta is important as it plays role in acute and chronic inflammatory diseases which are usually treated by reducing IL-1 $\beta$ activity (44). The significant reduction in IL-6 was also observed in yoga groups when compared to control groups in heart failure patients $(34,41,11)$. These findings suggest that yoga can act as a non- pharmacological

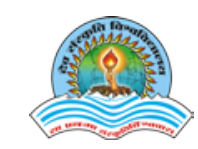


approach in reducing IL-6, IL-1, and TNF-alpha, which in present scenario, could potentially benefit COVID19 patients.

Potential impact of yoga on mental health Deteriorating mental health conditions during pandemic and increasing stress, anxiety, fear and depression could negatively affect immune system and increase the risk of acute respiratory infections (45). Ministry of AYUSH, government of India has advised to follow Yoga and Ayurveda in one's lifestyle to remain mentally healthy and boost up immunity to prevent oneself from getting infected of coronavirus (46). During the time of this pandemic outbreak, one could easily see the deterioration of mental health due to fear, anxiety, depression, and stress.

Many studies had reported the negative mental health conditions of the people during a pandemic outbreak. Some qualitative studies reported fear (47) and sleep disorders related to anxiety during quarantine at the time of SARS outbreak (48). Psychological health needs to be very strong in order to cope with any type of disease. A study conducted by Andersen et al. (1998) reported that stress inhibited the cellular immune responses including NK cells and T-cell responses (7). These reports evidenced that psychological and physiological stress needs to be lowered down in order to boost immunity against the infectious diseases.

Owing to the present condition, the rising mental health consequences during COVID19 pandemic requires early prevention and intervention. Yoga and meditation practices have been proved beneficial in managing different levels of stress, anxiety and depression as documented in many studies. A Study was conducted on 51 COVID19 patients, who were randomized into experimental and control groups; the experimental group received 30 minutes of progressive muscle relaxation for five consecutive days in a week for 45 days whereas the control group was on their usual routine; after the intervention program the average sleep quality and anxiety was significantly improved in the experimental group compared to the control group (49).

Yogic practices also improve general and psychological wellbeing and mental health in daily life. In a study on Urban population for general wellbeing, a positive improvement was seen by the yoga intervention program, which contained jal-neti, sutra neti, kunjal-kriya and kapalbhati, asana, pranayama and meditation for 12 weeks (50). A systematic review of effect of Yoga on psychological disorders such as depression, anxiety, obsessive compulsive disorder (OCD) and schizophrenia was conducted using 30 articles published between years 2002 to 2014; the result indicated most significant improvement in the condition of depression (51). Another study reported the efficacy of yoga on anxiety, depression and stress on 68 breast cancer women undergoing the radiotherapy treatment (52). In one of the study, it was found that stress, anxiety and depression in 31 patients undergoing hemodialysis were significantly reduced $(p<0.001)$ from baseline scores by the two months practice of Hatha-yoga package and also compared to that of control group (53). In addition, a four week intervention of Sudarshan-kriya, a yogic breathing practice along with guided meditation was given to 31 patients with generalized anxiety disorders (GAD); the results showed significant reduction in anxiety scores compared to the baseline (54). All these evidences indicated the promising benefits of yoga practices in improving the mental health conditions and promoting the psychological well being of the person, thus, indicating potential role of Yogic practices for mental health especially in COVID19 era.

\section{Conclusion}

First half of year 2020 has proven a challenging time for the world in the time of COVID19 pandemic. With dire need of finding treatment solutions and support for COVID19 patients, the present study shed a light that Yogic practices could potentially aid in the fight against COVID19. Yoga helped in reducing inflammatory factors CRP, harmful cytokines - Interleukin-1-beta, interleukin IL-6, and

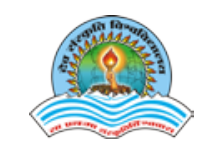


TNF- alpha. It was also helpful in increasing immunoglobins IgG, cytokines interleukin-12 and interferon- $\gamma$ (INF- $\gamma$ ) for improving immunity. In diabetic patients yoga was beneficial in increasing insulin sensitivity, glucose tolerance, glycemic control, and in reducing HbA1C level. Apart from this yoga significantly reduced systolic and diastolic blood pressure; in reducing the symptoms of asthma, hypoxemia, dyspnea and other respiratory disorders, by improving pulmonary function, and oxygen saturation in blood. It was also useful in reducing stress, depression, and anxiety, and also improved general well being, happiness, quality of life and sleep.

Summarily, the presented review of previously published studies on Yoga evidenced the beneficial effect of yoga in improving the immune function, diabetic-cardiovascular-respiratory conditions, and mental health, which is very important during the period of incubation and progression of COVID19 towards severe condition globally, thus, indicating potential utility of yoga as an adjunct therapy in the prevention and management of COVID19.

\section{References}

1. Tesini B. Coronaviruses and Acute Respiratory Syndromes (COVID19, MERS, and SARS) - Infectious Diseases - MSD Manual Professional Edition [Internet]. MSD Manual Professional Edition. 2020 [cited 26 June 2020]. Available from: https://www.msdmanuals.com/professional/infectiousdiseases/respiratory-viruses/coronaviruses-and-acuterespiratory-syndromes-COVID19,-mers,-and-sars

2. Kandola A. Coronavirus (COVID19) origin: Cause and how it spreads [Internet]. Medicalnewstoday.com. 2020 [cited 6 June 2020]. Available from: https://www.medicalnewstoday.com/articles/coronaviru s-causes

3. Coronavirus disease 2019 (COVID19) - Diagnosis and treatment - Mayo Clinic [Internet]. Mayoclinic.org. 2020 [cited 6 June 2020]. Available from: https://www.mayoclinic.org/diseasesconditions/coronavirus/diagnosis-treatment/drc20479976

4. Guan WJ, Liang WH, Zhao Y, Liang HR, Chen ZS, Li YM, Liu XQ, Chen RC, Tang CL, Wang T, Ou CQ. Comorbidity and its impact on 1590 patients with
COVID19 in China: A Nationwide Analysis. European Respiratory Journal. 2020 May 1;55(5). https://doi.org/10.1183/13993003.00547-2020

5. Cascella M, Rajnik M, Cuomo A, Dulebohn SC, Di Napoli R. Features, evaluation and treatment coronavirus (COVID19). InStatpearls [internet] 2020 Mar 8. StatPearls Publishing.

6. Wang C, Pan R, Wan X, Tan Y, Xu L, Ho CS, Ho RC. Immediate psychological responses and associated factors during the initial stage of the 2019 coronavirus disease (COVID19) epidemic among the general population in China. International journal of environmental research and public health. 2020 Jan;17(5):1729. https://doi.org/10.3390/ijerph17051729

7. Andersen BL, Farrar WB, Golden-Kreutz D, Kutz LA, MacCallum R, Courtney ME, Glaser R. Stress and immune responses after surgical treatment for regional breast cancer. JNCI: Journal of the National Cancer Institute. $1998 \quad$ Jan 7;90(1):30-6. https://doi.org/10.1093/jnci/90.1.30

8. Torales J, O'Higgins M, Castaldelli-Maia JM, Ventriglio A. The outbreak of COVID19 coronavirus and its impact on global mental health. International Journal of Social Psychiatry. 2020 Mar 31:0020764020915212. https://doi.org/10.1177/0020764020915212

9. Sahay BK. Yoga and diabetes. The Journal of the Association of Physicians of India. 1986 Sep;34(9):645.

10. Innes KE, Vincent HK. The influence of yoga-based programs on risk profiles in adults with type 2 diabetes mellitus: a systematic review. Evidence-Based Complementary and Alternative Medicine. 2007 Dec $1 ; 4$.

https://doi.org/10.1093/ecam/nel103

11. Chen N, Xia X, Qin L, Luo L, Han S, Wang G, Zhang $\mathrm{R}$, Wan Z. Effects of 8-week Hatha yoga training on metabolic and inflammatory markers in healthy, female Chinese subjects: a randomized clinical trial. BioMed research international. 2016 Oct;2016. https://doi.org/10.1155/2016/5387258

12. Jindal N, Joshi NP. Comparative study of Vamana and Virechanakarma in controlling blood sugar levels in diabetes mellitus. Ayu. 2013 Jul;34(3):263. https://doi.org/10.4103/0974-8520.123115

13. Pawan K, Ishwar B. Effect of yogic practices on glycated haemoglobin (Hba1c) level of type II diabetese mellitus in urban adults.

14. Cade WT, Reeds DN, Mondy KE, Overton ET, Grassino J, Tucker S, Bopp C, Laciny E, Hubert S, Lassa-Claxton S, Yarasheski KE. Yoga lifestyle intervention reduces blood pressure in HIV-infected adults with cardiovascular disease risk factors. HIV medicine. $2010 \mathrm{Jul} ; 11(6): 379-88$. https://doi.org/10.1111/j.1468-1293.2009.00801.x 
15. Hagins M, Selfe T, Innes K. Effectiveness of yoga for hypertension: systematic review and meta-analysis. Evidence-Based Complementary and Alternative Medicine. 2013 Jan 1;2013. https://doi.org/10.1155/2013/649836

16. Tyagi A, Cohen M. Yoga and hypertension: a systematic review. Alternative Therapies in Health and Medicine. 2014;20(2):32-59.

17. Murugesan R, Govindarajulu N, Bera TK. Effect of selected yogic practices on the management of hypertension. Indian Journal of Physiology and Pharmacology. 2000 Apr 10;44(2):207-10.

18. Xu Z, Shi L, Wang Y, Zhang J, Huang L, Zhang C, Liu S, Zhao P, Liu H, Zhu L, Tai Y. Pathological findings of COVID19 associated with acute respiratory distress syndrome. The Lancet respiratory medicine. $2020 \mathrm{Apr}$ 1;8(4):420-2. https://doi.org/10.1016/S2213-2600(20)30076-X

19. Rabago D, Zgierska A, Mundt M, Barrett B, Bobula J, Maberry R. Efficacy of daily hypertonic saline nasal irrigation among patients with sinusitis: a randomized controlled trial. Journal of Family Practice. 2002 Dec 1;51(12):1049-55.

20. Tano L, Tano K. A daily nasal spray with saline prevents symptoms of rhinitis. Acta oto-laryngologica. 2004 Nov 1;124(9):1059-62. https://doi.org/10.1080/00016480410017657

21. Lin L, Yan W, Zhao X. Treatment of allergic rhinitis with normal saline nasal irrigation at different temperature. Zhonghua er bi yan hou tou Jing wai ke za zhi= Chinese Journal of Otorhinolaryngology Head and Neck Surgery. 2014 Feb 1;49(2):109-14..

22. Nagendra HR, Nagarathna R. An integrated approach of yoga therapy for bronchial asthma: a 3-54-month prospective study. Journal of asthma. 1986 Jan $1 ; 23(3): 123-37$. https://doi.org/10.3109/02770908609077486

23. Ranjita R, Hankey A, Nagendra HR, Mohanty S. Yogabased pulmonary rehabilitation for the management of dyspnea in coal miners with chronic obstructive pulmonary disease: a randomized controlled trial. Journal of Ayurveda and integrative medicine. $2016 \mathrm{Jul}$ 1;7(3):158-66. https://doi.org/10.1016/j.jaim.2015.12.001

24. Spicuzza L, Gabutti A, Porta C, Montano N, Bernardi L. Yoga and chemoreflex response to hypoxia and hypercapnia. The Lancet. 2000 Oct 28;356(9240):14956. https://doi.org/10.1016/S0140-6736(00)02881-6

25. Bernardi L, Spadacini G, Bellwon J, Hajric R, Roskamm H, Frey AW. Effect of breathing rate on oxygen saturation and exercise performance in chronic heart failure. The Lancet. 1998 May 2;351(9112):130811.

Page $\mathbf{3 0}$ of 31

ISSN: 2279-0578 (PRINT); 2582-4589 (ONLINE)

PUBLISHED BY DEV SANSKRITI VISHWAVIDYALAYA, HARIDWAR, INDIA
https://doi.org/10.1016/S0140-6736(97)10341-5

26. Abel AN, Lloyd LK, Williams JS. The effects of regular yoga practice on pulmonary function in healthy individuals: a literature review. The Journal of Alternative and Complementary Medicine. 2013 Mar 1;19(3):185-90. https://doi.org/10.1089/acm.2011.0516

27. Sodhi C, Singh S, Dandona PK. A study of the effect of yoga training on pulmonary functions in patients with bronchial asthma. Indian J Physiol Pharmacol. 2009 Apr;53(2):169-74.

28. Nagarathna R, Nagendra HR. Yoga for bronchial asthma: a controlled study. Br Med J (Clin Res Ed). 1985 Oct 19;291(6502):1077-9. https://doi.org/10.1136/bmj.291.6502.1077

29. Liu XC, Pan L, Hu Q, Dong WP, Yan JH, Dong L. Effects of yoga training in patients with chronic obstructive pulmonary disease: a systematic review and meta-analysis. Journal of thoracic disease. 2014 Jun;6(6):795.

30. Donesky-Cuenco D, Nguyen HQ, Paul S, CarrieriKohlman V. Yoga therapy decreases dyspnea-related distress and improves functional performance in people with chronic obstructive pulmonary disease: a pilot study. The journal of alternative and complementary medicine. 2009;15(3):225-34.

https://doi.org/10.1089/acm.2008.0389

31. Fulambarker A, Farooki B, Kheir F, Copur AS, Srinivasan L, Schultz S. Effect of yoga in chronic obstructive pulmonary disease. American journal of therapeutics. 2012 Mar 1;19(2):96-100. https://doi.org/10.1097/MJT.0b013e3181f2ab86

32. Nagendra HR. Yoga for COVID19. International Journal of Yoga. 2020 May 1;13(2):87. https://doi.org/10.4103/ijoy.IJOY_27_20

33. Shi Y, Wang Y, Shao C, Huang J, Gan J, Huang X, Bucci E, Piacentini M, Ippolito G, Melino G. COVID19 infection: the perspectives on immune responses. 2020 https://doi.org/10.1038/s41418-020-0530-3

34. Pullen PR, Thompson WR, Benardot D, Brandon LJ, Mehta PK, Rifai LU, Vadnais DS, Parrott JM, Khan BV. Benefits of yoga for African American heart failure patients. Med Sci Sports Exerc. 2010 Apr 1;42(4):651-7. https://doi.org/10.1249/MSS.0b013e3181bf24c4

35. Infante JR, Peran F, Rayo JI, Serrano J, Dominguez ML, Garcia L, Duran C, Roldan A. Levels of immune cells in transcendental meditation practitioners. International journal of yoga. 2014 Jul;7(2):147. https://doi.org/10.4103/0973-6131.133899

36. Lim SA, Cheong KJ. Regular yoga practice improves antioxidant status, immune function, and stress hormone releases in young healthy people: a randomized, doubleblind, controlled pilot study. The Journal of Alternative and Complementary Medicine. 2015 Sep 1;21(9):530-8. 
https://doi.org/10.1089/acm.2014.0044

37. Schoenborn JR, Wilson CB. Regulation of interferon- $\gamma$ during innate and adaptive immune responses. Advances in immunology. 2007 Jan 1;96:41-101. https://doi.org/10.1016/S0065-2776(07)96002-2

38. Del Vecchio M, Bajetta E, Canova S, Lotze MT, Wesa A, Parmiani G, Anichini A. Interleukin-12: biological properties and clinical application. Clinical Cancer Research. 2007 Aug 15;13(16):4677-85. https://doi.org/10.1158/1078-0432.CCR-07-0776

39. Gopal A, Mondal S, Gandhi A, Arora S, Bhattacharjee J. Effect of integrated yoga practices on immune responses in examination stress-A preliminary study. International journal of yoga. 2011 Jan;4(1):26. https://doi.org/10.4103/0973-6131.78178

40. Naoroibam R, Metri KG, Bhargav H, Nagaratna R, Nagendra HR. Effect of Integrated Yoga (IY) on psychological states and CD4 counts of HIV-1 infected Patients: A Randomized controlled pilot study. International journal of yoga. 2016 Jan;9(1):57. https://doi.org/10.4103/0973-6131.171723

41. Kiecolt-Glaser JK, Bennett JM, Andridge R, Peng J, Shapiro CL, Malarkey WB, Emery CF, Layman R, Mrozek EE, Glaser R. Yoga's impact on inflammation, mood, and fatigue in breast cancer survivors: a randomized controlled trial. Journal of Clinical Oncology. 2014 Apr 1;32(10):1040. https://doi.org/10.1200/JCO.2013.51.8860

42. Bower JE, Greendale G, Crosswell AD, Garet D, Sternlieb B, Ganz PA, Irwin MR, Olmstead R, Arevalo $\mathrm{J}$, Cole SW. Yoga reduces inflammatory signaling in fatigued breast cancer survivors: a randomized controlled trial. Psychoneuroendocrinology. 2014 May 1;43:20-9.

https://doi.org/10.1016/j.psyneuen.2014.01.019

43. Zhang W, Zhao Y, Zhang F, Wang Q, Li T, Liu Z, Wang J, Qin Y, Zhang X, Yan X, Zeng X. The use of anti-inflammatory drugs in the treatment of people with severe coronavirus disease 2019 (COVID19): The experience of clinical immunologists from China. Clinical Immunology. 2020 Mar 25:108393. https://doi.org/10.1016/j.clim.2020.108393

44. Dinarello CA. Interleukin-1 in the pathogenesis and treatment of inflammatory diseases. Blood, The Journal of the American Society of Hematology. 2011 Apr 7;117(14):3720-32.

https://doi.org/10.1182/blood-2010-07-273417

45. Maxwell L, Barrett B, Chase J, Brown R, Ewers T. Selfreported mental health predicts acute respiratory infection. WMJ: official publication of the State Medical Society of Wisconsin. 2015 Jun;114(3):100.

46. Ayurveda's immunity boosting measures for self care during COVID 19 crisis [Internet]. www.ayush.gov.in.
2020 [cited June 2020]. Available from: https://www.ayush.gov.in/docs/123.pdf

47. DiGiovanni C, Conley J, Chiu D, Zaborski J. Factors influencing compliance with quarantine in Toronto during the 2003 SARS outbreak. Biosecurity and bioterrorism: biodefense strategy, practice, and science. 2004 Dec 1;2(4):265-72. https://doi.org/10.1089/bsp.2004.2.265

48. Pan PJ, Chang SH, Yu YY. A support group for homequarantined college students exposed to SARS: learning from practice. The Journal for Specialists in Group Work. 2005 Dec 1;30(4):363-74. https://doi.org/10.1080/01933920500186951

49. Liu K, Chen Y, Wu D, Lin R, Wang Z, Pan L. Effects of progressive muscle relaxation on anxiety and sleep quality in patients with COVID19. Complementary Therapies in Clinical Practice. 2020 Mar 6:101132. https://doi.org/10.1016/j.ctcp.2020.101132

50. Prasad G, Bhardwaj I, Vishwavidyalaya GK, Haridwar U. Effect of Comprehensive Yogic Practices on General Well Being of Urban Population. Available fromhttp://indianyoga.org/wp-content/uploads/2018/03/v7issue1-article7.pdf

51. Shroff FM, Asgarpour M. Yoga and mental health: A review. Journal of Physiotherapy and Physical Rehabilitation. 2017;2:2573-0312. https://doi.org/10.4172/2573-0312.1000132

52. Banerjee B, Vadiraj HS, Ram A, Rao R, Jayapal M, Gopinath KS, Ramesh BS, Rao N, Kumar A, Raghuram $N$, Hegde S. Effects of an integrated yoga program in modulating psychological stress and radiation-induced genotoxic stress in breast cancer patients undergoing radiotherapy. Integrative cancer therapies. 2007 Sep;6(3):242-50. https://doi.org/10.1177/1534735407306214

53. Tayyebi A, babahaji M, SADEGHI SM, EBADI A, eynollahi B. Study of the effect of Hatha Yoga exercises on stress, anxiety and depression among hemodialysis patients.

54. Katzman MA, Vermani M, Gerbarg PL, Brown RP, Iorio C, Davis M, Cameron C, Tsirgielis D. A multicomponent yoga-based, breath intervention program as an adjunctive treatment in patients suffering from generalized anxiety disorder with or without comorbidities. International journal of yoga. 2012 Jan;5(1):57.

https://doi.org/10.4103/0973-6131.91716 